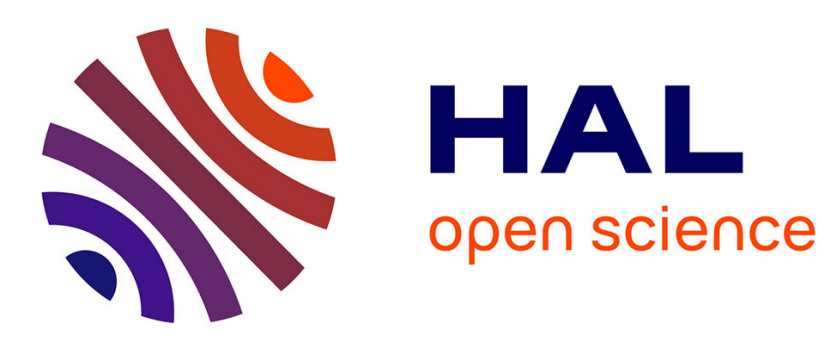

\title{
The energy balance of the material breaking under the action of the high pressure water jet
}

\author{
G. Dumitru, G. Zgura
}

\section{To cite this version:}

G. Dumitru, G. Zgura. The energy balance of the material breaking under the action of the high pressure water jet. Journal de Physique IV Proceedings, 1994, 04 (C8), pp.C8-759-C8-764. 10.1051/jp4:19948117 . jpa-00253359

\section{HAL Id: jpa-00253359 https://hal.science/jpa-00253359}

Submitted on 1 Jan 1994

HAL is a multi-disciplinary open access archive for the deposit and dissemination of scientific research documents, whether they are published or not. The documents may come from teaching and research institutions in France or abroad, or from public or private research centers.
L'archive ouverte pluridisciplinaire HAL, est destinée au dépôt et à la diffusion de documents scientifiques de niveau recherche, publiés ou non, émanant des établissements d'enseignement et de recherche français ou étrangers, des laboratoires publics ou privés. 


\title{
The energy balance of the material breaking under the action of the high pressure water jet
}

\author{
G.M. Dumitru and G. Zgura \\ University Politehnica of Bucharest, Department Technology of the Materials and Welding, \\ Splaiul Independetei 313, Sector 6, 77206 Bucharest, Romania
}

\begin{abstract}
Résumé: Pour déterminer correctement les paramétres de découpage à jet d'eau à haute pression, il est nécessaire à étudier le mécanisme de rupture du matériau sous l'action du jet d'eau. De l'analyse du comportement du matériau sous l'action du jet d'eau à haute pression, ayant une vitesse supersonique, il résulte que le processus de rupture du matériau du découpage à jet d'eau est un processus micro-érosif. On étudie la balance énergétique de la rupture microérosive du matériau, en considérant l'énergie de nucléation de la microfissure, la variation de l'énergie intérieure dûe à l'apparition de la microfissure, l'énergie dissipée pour vaincre la résistance du matériau à l'extension de la fissure et l'énergie cinétique des parties en mouvement; on détermine, ainsi, l'énergie nécessaire pour le découpage du matériau. Par comparaison au pouvoir disponible du jet d'eau à haute pression, on établit la relation pour le calcul de la vitesse maximale de découpage à jet d'eau à haute pression.
\end{abstract}

\begin{abstract}
For a correct determination of the cutting process parameters by high pressure water jet, it is necessary to study the breaking mechanism of the material under the action of the water jet. From the analysis of the material behavior under high pressure water jet, moving at supersonic speed, it appears like a micro-erosive process. We study the energy balance of the micro-erosive breaking of the material taking into account the nucleation energy of the microcracking, the internal energy variation due to the micro-crack appearance, the dissipated energy in order to overcome the material resistance to the crack extension and the kinetic energy of the moving parts; we determine, in that way, the necessary energy for the material cutting. By comparison with the disposal power of the high pressure water jet, we establish the calculus relation of the maximum cutting speed by high pressure water jet.
\end{abstract}

\section{INTRODUCTION}

The main parameters of the material cutting process by high pressure water jet are: water jet pressure, $p$, diameter of the cutting nozzle, $d$, distance from the nozzle to the material surface, $h$ and cutting speed, $v_{t}$. For a correct evaluation of these parameters, it is necessary to study the breaking mechanism of the material under the action of the high pressure water jet, the energy balance of the material breaking, the correlation between the energy required by the material breaking and the parameters of the cutting process. In this way, we establish the calculus relation of the maximum cutting speed by high pressure water jet. 


\section{THE WATER JET IMPACT ON THE MATERIAL}

The impact at supersonic speed of the high pressure water jet on the material leads to the appearance of some shock waves sources, $\mathrm{O}, \mathrm{O}_{1}, \mathrm{O}_{1}$, which propagate both into the material and the water jet. By the propagation of the supersonic shock waves into the water jet the Mach pressure space is formed and causes the spraying of the water jet (Fig. 1) [1]. The spraying of the water jet entails the disappearance of the supersonic shock wave sources and of the Mach pressure space. The water jet is recompacted and during a new impact on the material, a new shock wave is propagated into the material and into the water jet. Once again the Mach pressure space appears, the new spraying of the water jet occurs and the phenomenon is repeated. The result is that the water jet has an intermitent action on the material, similar to the "pick-hammer".

Due to the "pick-hammer effect", the repeated shock

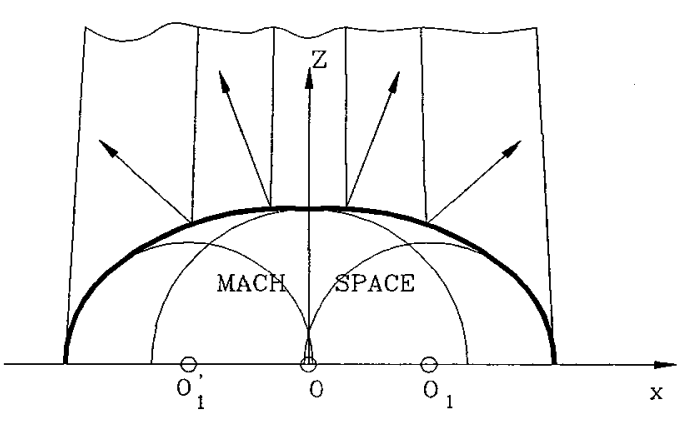

Fig. 1 waves are transmitted into the material and reflected on the back surface of the material. These waves interfere with the incident shock waves (see the circular points in the figure 2).

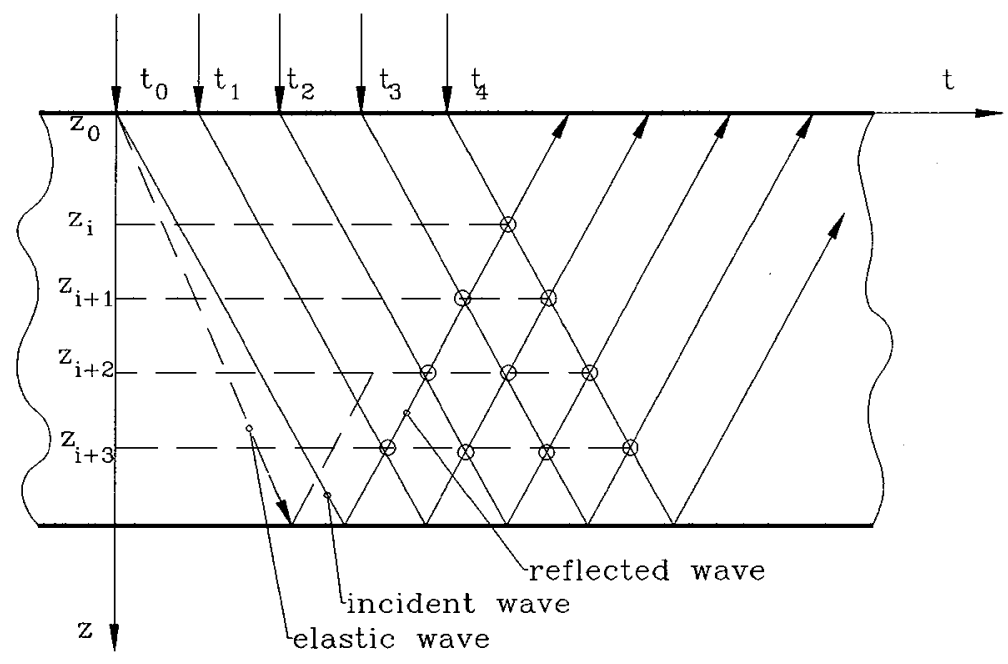

Fig. 2

At the interference points the material reaches its maximum tensile stress, given by the relation [2]:

$$
\sigma=\rho u \cdot\left(c+\chi_{1} u+\chi_{2} u^{2}\right)
$$

where $\sigma$ is the stress tension, $\rho$ is the density and $c$ is the sound speed for the material to be cut, $u$ is the impact speed of the water jet, $\chi_{1}$ and $\chi_{2}$ are material constants.

According to [3], the impact speed of the high pressure water jet on the material, assuming that the water is compressible and viscid at high pressure and the flow of the water in the current tube is turbulent, is given by:

$$
u=\sqrt{\frac{2 \cdot \epsilon}{\xi \cdot \rho} \cdot \ln (1+\beta p)}
$$


where $\epsilon$ is the elasticity modulus of the water, $\xi$ is the coefficient of the loss energy in the nozzle, $\rho$ is the water density at atmospheric pressure and $\beta$ is the compressibility coefficient of the water.

For normal cutting by high pressure water jet, the value of the water jet impact speed at which the material may be cut corresponds to a value of tensile stress at these points so great that the nucleation conditions for the micro-cracks, their growth, propagation and the final breaking of the material are met. According to [3], the minimum pressure required to fulfil the conditions of nucleation, growth and propagation of the micro-cracks and the detaching of the material particles is given by the relation:

$$
p_{\min }=1.93 \cdot \psi \cdot \sqrt{\frac{1}{1-v^{2}}} \cdot R
$$

where $\psi$ is a coefficient which depends on the material to be cut, $v$ is Poisson's coefficient and $\mathrm{R}$ is the breaking strength of the material to be cut.

According to the interaction model of the water jet with the material to be cut (Fig. 2) and the above mentioned notions, it follows that the breaking of the material under the high pressure water jet is a micro-erosive process [3]. This fact is also confirmed by the shape and size of the particles produced.

\section{ENERGY BALANCE}

The energy balance for the process of nucleation and extension of the micro-crack a distance $\Delta \mathrm{a}$ into the material is obtained by letting the equivalent energy of the mechanical work $\Delta \mathrm{W}$ performed by the external forces be given by the sum of the nucleation energy of the crack $\Delta W_{F}$, the variation of the internal energy $\Delta U$, the dissipated energy in overcoming the material strength during micro-crack extension $\Delta \mathrm{W}_{\mathrm{R}}$ and the kinetic energy of the moving parts $\Delta \mathrm{E}[4]$ :

$$
\Delta W=\Delta W_{F}+\Delta U+\Delta W_{R}+\Delta E
$$

Taking the limit, when $\Delta$ a tends to 0 , we obtain:

$$
\frac{d W}{d a}=\frac{d W_{F}}{d a}+\frac{d U}{d a}+\frac{d W_{R}}{d a}+\frac{d E}{d a}
$$

In order to find the energy required for detaching a material particle during the cutting process, it is necessary to determine each term of the relation (5). For crystalline materials, the micro-crack could be treated like an extended dislocation of length $2 a$ and vector $D=n b$, where $n$ is the number of dislocations and $b$ is the Burgers vector.

We could consider that the energy required to nucleate the micro-crack is equivalent to the associated dislocation energy [4]:

$$
W_{F}=\frac{\mu n^{2} \cdot b^{2}}{4 \cdot(1-v)} \cdot a
$$

According to [4], the number of dislocations $\mathrm{n}$ in equilibrium in a slipping band having the length $\mathrm{L}$ under the action of an applied stress $\sigma$ is:

so that:

$$
n=\alpha \cdot \frac{\pi \cdot L \cdot \sigma}{\mu \cdot b}
$$

$$
n \cdot b=\frac{\alpha \pi \cdot L \cdot \sigma}{\mu}
$$

For edge dislocations $\alpha=1-v$.

Replacing (8) into (6) we obtain:

$$
W_{F}=\frac{\pi^{2}}{4} \cdot \frac{1-v}{\mu} \cdot L^{2} \cdot \sigma^{2} a
$$

where $\mu$ is the modulus of elasticity in shear, $\mathrm{L}$ is the length of the dislocation slip band and $\sigma$ is the applied stress. Since cutting by high pressure water jet is a micro-erosive process, the particles removed from the material by cutting are comparable in size to crystals, so we may approximate the length of the slip band $L$ to the crack length, i.e.: 
where $\mathbf{k}$ is a material coefficient.

$$
L=k \cdot 2 \cdot a
$$

Noting that $\mu=E / 2 \cdot(1+v)$ and replacing (10) into (9) we obtain:

$$
W_{F}=k^{2} \pi^{2} \cdot \frac{1-v^{2}}{E} \cdot a^{3} \cdot \sigma^{2}
$$

The variation of the internal energy during the change from a non-cracked to a cracked plate could be evaluated from the elastic energy associated with the presence of micro-crack of length 2 a [4]:

$$
U=-\frac{8 \cdot\left(1-v^{2}\right)}{3 \cdot E} \cdot a^{3} \cdot o^{2}
$$

The term $\mathrm{dW}_{\mathrm{R}} / \mathrm{da}$ from equation (5) represents the whole mechanical work performed during unit extension of the crack and includes both the surface energy required by the creation of new surfaces and the energy absorbed by plastic deformation in the adjacent zone of the crack front. The mechanical work performed to extend the crack by $\delta \mathrm{a}$ (Fig. 3) will be determined taking into account the tension $\sigma_{y y}$ applied on the crack face over the range a $<$ $|\mathrm{x}|<\mathrm{a}+\delta \mathrm{a}$ required by the crack closing till the initial length; the mechanical work performed by $\sigma_{y y}(x, 0)$ when it moves on the distance $\mathrm{v}(\mathrm{x}, 0)$ in order to close the micro-crack, is equivalent to the mechanical work consumed for the opening of the micro-crack on the length $\delta$.

In case that a crack stressed by a pression uniformly distributed on the edges of the crack, the expression of the tension $\sigma_{\mathrm{yy}}(\mathrm{x}, 0)$ is [4]:

$$
\sigma_{y y}(x, 0)=\frac{K}{\sqrt{2 \cdot \pi \cdot(x-a)}} \cdot b
$$

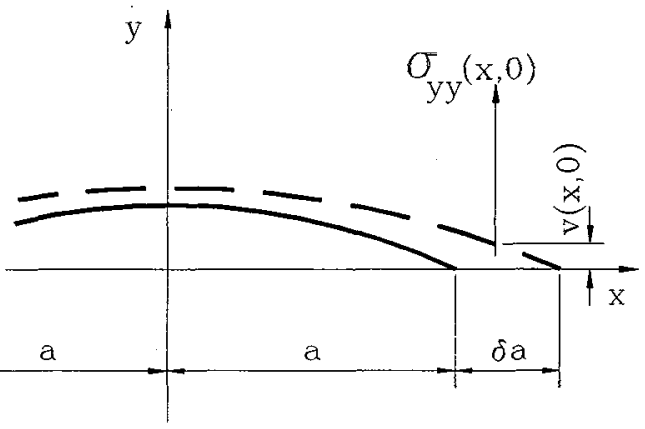

where $\mathrm{K}$ is the stress intensity factor.

The moving $v(x, 0)$ is $[4]$ :

$$
v(x, 0)=\frac{4 \cdot\left(1-v^{2}\right)}{E} \cdot K \cdot \sqrt{\frac{a+\delta a-x}{2 \pi}}
$$

Fig. 3

We define, conventionally, a "force" $G$ required by the extension of the crack; the mechanical work required by extension of the crack is:

$$
L_{F}=G d a=\int_{a}^{a+\delta a} \sigma_{y y}(x, 0) \cdot v(x, 0) d x
$$

Replacing (13) and (14) by (15) and integrating we obtain:

$$
G=\frac{1-v^{2}}{E} \cdot K^{2}
$$

For a round surface crack under uniform stress, as may be assumed for cutting by high pressure water jet, the stress intensity factor has the form [4]:

so that:

$$
K=1.222 \sigma \cdot(\pi \cdot a)^{1 / 2}
$$

$$
G=\frac{1-v^{2}}{E} \cdot 1.493 \pi \cdot a \cdot \sigma^{2}
$$

The elementary mechanical work $\mathrm{dW}_{\mathrm{R}}$ consumed when an element $\mathrm{dl}$ of the crack front extends a distance da under the action of the crack extension force $\mathrm{G}$ is:

$$
d W_{R}=G \cdot d l \cdot d a
$$

where $\mathrm{dl}=2 \cdot \pi$ a for the round crack and (19) becomes: 


$$
d W_{R}=2 \pi \cdot G \cdot a \cdot d a
$$

Replacing (18) by (20) and integrating, we obtain:

$$
W_{R}=0.84 \cdot \pi^{2} \cdot \frac{1-v^{2}}{E} \cdot a^{3} \cdot \sigma^{2}
$$

Since the movement of the parts during the cracking process are extremely small the kinetic energy term may be ignored, so replacing (11), (12) and (21) into (5) we obtain:

$$
W=\left(k^{2}-1.22\right) \cdot \pi^{2} \cdot \frac{1-v^{2}}{E} \cdot a^{3} \cdot \sigma^{2}
$$

$\mathrm{W}$ is the energy required in cutting off a material particle which has a semi-disk shape and the volume $\mathrm{V}_{\mathrm{p}}$ :

$$
V_{p}=\frac{\pi \cdot a^{2}}{2} s_{d}
$$

where $s_{d}$ is the thickness of the semi-disk.

The minimal power required for cutting will be:

$$
P_{u}=\frac{1}{k_{v}} \cdot \frac{V_{t}}{V_{p}} \cdot \frac{W}{t_{t}}
$$

where $\mathrm{k}_{\mathrm{v}}$ is a coefficient which takes into account that the particles removed during cutting have different sizes and shapes, $V_{t}$ is the cutting volume and $t_{t}$ is the cutting time.

The cutting volume is calculated by the relation:

$$
V=b: l
$$

where $b$ is the cutting width, $s$ is the thickness of the material to be cut and 1 is the cutting length.

Taking into account the cutting speed expression:

$$
v_{t}=\frac{l}{t_{t}}
$$

and using a shape coefficient for the removed particles, $\mathrm{K}_{\mathrm{p}}=\mathrm{a} / \mathrm{s}_{\mathrm{d}}$, according to relations (22), (23), (24), (25) and (26) we obtain:

$$
P_{u}=\frac{2 \pi \cdot K_{p}}{K_{v}} \cdot(k-1.22) \cdot \frac{1-v^{2}}{E} \cdot \sigma^{2} \cdot b s v_{\xi}
$$

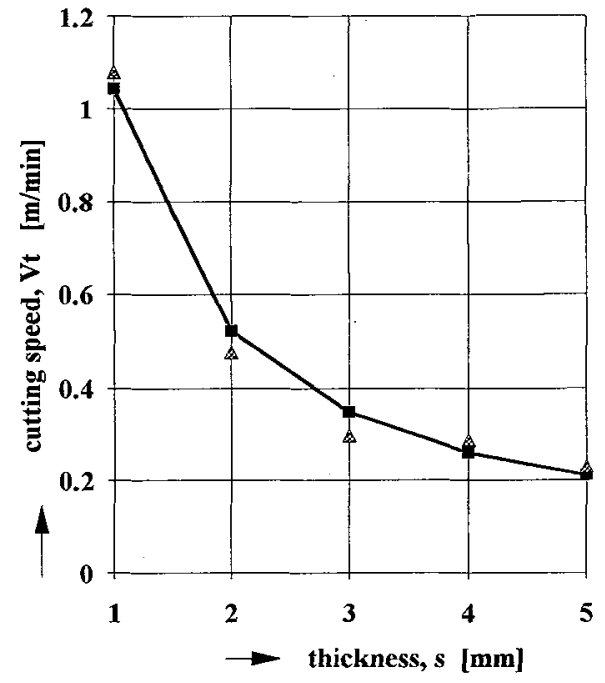

Fig. 4

Letting the efficiency of the cutting process be $\eta$ we obtain for the power required:

$$
P=\frac{2 \pi \cdot K_{p}}{\eta \cdot K_{v}} \cdot\left(k^{2}-1.22\right) \cdot \frac{1-v^{2}}{E} \cdot \sigma^{2} \cdot b \cdot s v_{t}
$$

Analyzing relation (28) we find that the cutting power by high pressure water jet depends on the structure and characteristics of the material to be cut $(\mathrm{k}, \mathrm{v}, \mathrm{E}, \sigma)$, on the cutting size $(\mathrm{b}, \mathrm{s})$ and on the cutting speed $v_{l}$. In order to make the cutting possible, it is necessary that the jet power $P_{j}$ be greater than the required power $\mathrm{P}$ :

$$
P_{j}>P
$$

The power of the high pressure water jet is:

$$
P_{j}=C_{f} \cdot \frac{\pi \cdot d^{2}}{4} u p
$$

where $C_{f}$ is the shape coefficient of the speed distribution profile by nozzle section, $d$ is the nozzle diameter, $\mathrm{u}$ is the axial speed of the water jet at the nozzle outlet and $\mathrm{p}$ is the jet pressure.

From the relations (28), (29) and (30) the cutting speed by high pressure water jet is given by: 
Noting that:

$$
v_{t}=\frac{\eta \cdot K_{v}}{8 \cdot K_{p}} \cdot \frac{C_{f}}{k^{2}-1.22} \cdot \frac{d^{2} p u}{b \cdot s} \cdot \frac{E}{\left(1-v^{2}\right) \cdot \sigma^{2}}
$$

the relation (31) becomes:

$$
C=C_{f} \cdot \frac{K_{v}}{8 \cdot K_{p} \cdot\left(k^{2}-1.22\right)} \eta
$$

$$
v_{t}=C \cdot \frac{d^{2} p \cdot u}{b \cdot s} \cdot \frac{E}{\left(1-v^{2}\right) \sigma^{2}}
$$

The diagram from the figure 4 presents the correlation between the cutting speed and the thickness of the material to be cut. The experimental testings were performed as-cast aluminum samples, using $0.2 \mathrm{~mm}$ diameter nozzle, at a $400 \mathrm{MPa}$ pressure. The theoretical values, determined in concordance with the relation (33), are marked by square points and the experimental data are marked by triangular points.

\section{CONCLUSION}

The experimental testing showed that the breaking of the material at the high pressure water jet cutting was a micro-erosive process.

The good concordance between the theoretical values and the experimental data confirmed the proposed material breaking physical model and validated the relation (33).

\section{References}

1. Beutin E.P. - L'utilisation des chocs fluides - Metall 27, nr. 1, 1973

2. Bowden F.P. - Some experiments on the deformation of solids by intens stress waver Conference "Les ondes de detonation" - Centre National de la Recherche Scientifique Paris, 1962

3. Dumitru G.M. - Contributions to the jet cutting technology of the materials - doctor's thesis University POLITEHNICA of Bucharest, 1991

4. Cioclov D. - Fracture Mechanics of the Materials - Editura Academiei Romane, 1977 